\title{
The Acceptance of Telepresence Robots in Higher Education
}

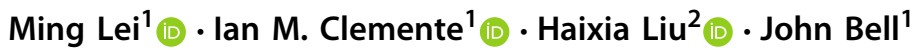

Accepted: 18 October 2021 / Published online: 27 January 2022

(c) The Author(s), under exclusive licence to Springer Nature B.V. 2021

\begin{abstract}
While telepresence robots have increasingly become accepted in diverse settings, the research on their acceptance in educational contexts has been underdeveloped. This study analyzed how the use intention of telepresence robots can be influenced by perceived usefulness, perceived ease of use, subjective norm, and perceived risk for students, faculty, and staff in higher education. Survey data were collected from 60 participants with direct operator experience with a variety of telepresence robots deployed in a large research university in the Midwest region of the United States. Path analysis results indicated that perceived usefulness was the only significant direct predictor of use intention of telepresence robots. Both perceived ease of use and subjective norm had a significant positive effect on perceived usefulness. Subjective norm also had a significant positive indirect effect on use intention, mediated by perceived usefulness. Perceived risk had a negative effect on perceived ease of use. These findings indicated that the usefulness of robots was central to operators' decisions to use telepresence robots. Therefore, design choice for telepresence robots should prioritize usefulness. Secondly, the design of telepresence robots should minimize complexity for the end user and minimize cognitive demand. Having nominal difficulty of use would also facilitate multiple embodiments by combining telepresence robots with other technologies to support more rich social interactions.
\end{abstract}

Keywords Tele-education robots $\cdot$ Remote learning by robot $\cdot$ Robot-mediated interview $\cdot$ Robot museum visitor . Videoconferencing robot $\cdot$ COVID-19

\section{Introduction}

Telepresence robot technology enables individuals to be present and active in a remote physical space with a surrogate robot body [1-3]. Telepresence robots are typically characterized by their support of videoconferencing and locomotion, which allows operators, the people who are controlling the robots, to see, hear, and move throughout their environment $[1,3]$. These capabilities support flexible applications, such as roving librarians moving throughout the stacks in a library [4]. Telepresence robots can also support telemanipulation, where operators interact with the environ-

Ming Lei

minglei@msu.edu

1 Department of Counseling, Educational Psychology and Special Education, Michigan State University, 620 Farm Lane, 513 Erickson Hall, East Lansing, MI 48824, USA

2 Integrative, Religious, and Intercultural Studies Department, Grand Valley State University, One Campus Dr, Allendale, MI 49401, USA ment with their surrogate robot bodies, such as with magnetic hands [5].

Despite telepresence robots' growing application in both K-12 and higher education [6-10], the theory on their acceptance has not been thoroughly developed. Although there exists a sizeable amount of scholarship describing the applications of telepresence robots, the specific research about the acceptance of telepresence robots has been concentrated within the healthcare field, and populations of robot operators who are often professionals or clients within the healthcare industry. This body of work includes research on the acceptance of telepresence robots by Macedonian caregivers and elderly people [11], nurses and care workers from Finland $[12,13]$, and teachers and students in the medical field in Sweden [14].

The prior scholarship on the acceptance telepresence robots has focused on what telepresence robots can or cannot do, and the challenges associated with their use, such as how well a telepresence robot can be used to navigate remote environments [15], the time it takes for operators to learn to use the robots [16], and users' ability to focus on task completion 
rather than robot operation [17]. Because of this emphasis on operators' views about the usefulness and ease of use of telepresence robots, the Technology Acceptance Model (TAM) has been applied to understand decision-making regarding their use[18]. Other predictors of use intention, such as subjective norm and perceived risk, have not been thoroughly described in the prior research.

The present study used the Technology Acceptance Model as a foundational framework to investigate the factors that predicted intention to use telepresence robots in higher education settings with a sample of telepresence robot operators with diverse backgrounds, quantities of experience, and platforms of telepresence robots.

\subsection{Telepresence Robots}

\subsubsection{Telepresence Robots and Design Thinking}

The design thinking perspective is useful for recognizing the dual nature of telepresence robots as being both the result of thoughtful design and instruments to inform future iterations.

This design thinking-based creative process of developing and prototyping robots in educational settings has been illustrated in many prior studies [19]. One recent example was the Stevie robot that has been tested in an independent living facility for adults and a summer camp for high school students [20]. After many cycles of design and evaluation, Stevie was not a terminus, but a significant development along the path toward designing robots that support greater independence and quality of life for people.

Similarly, the Pi Robot was developed over eight months through a collaboration between a research fellow and a robot enthusiast, who co-created a telepresence robot to meet the needs of a mobility-impaired user [21]. This process involved the augmentation of the robot's base features, the results of which Herring compared to commercially available alternatives.

As with the present study, the prior research that utilizes commercially available robots often includes discussions of design implications. One example includes the Romo robot, a mobile chassis compatible with several Apple mobile phones, including the iPhone 5, iPhone 5S, and iPhone 6S [22]. The Romo robot has been used to support language learning by giving operators the ability to practice interpersonal social skills in real-life settings [23]. In this study, the authors commented about design issues, namely that the small size of the robot relative to humans made human-robot interactions physically awkward. As a result, the intended benefit of the portability of the design also generated limitations (e.g., awkward human-robot interaction) under real world conditions.

In acknowledging the potential of current robots to inform future design, the authors of the present study believe that an increased understanding of how operators perceive contemporary robots can inform future iterations of commercial and noncommercial platforms that are more readily accepted.

\subsubsection{Caught Between Mainstream and Marginal}

Telepresence robots have existed in limbo between mainstream adoption and marginal use. On the one hand, telepresence robots have been in the mainstream cultural spotlight on many occasions. For example, in July 2015, President Obama greeted Alice Wong, the Disability Visibility Project Founder and Project Coordinator, with a telepresence robot [24], albeit for an event was primarily covered in technology-oriented media outlets, such as Wired and Popular Science [25, 26]. In an episode of situational comedy Community titled "Laws of Robotics and Party Rights" [27], telepresence robots were used to offer distance education opportunities to incarcerated individuals enrolled in the titular community college. More recently, in an episode of the fantasy comedy The Good Place titled "The snowplow" [28], telepresence robots were used in a scene to reflect a futuristic, voice activated super classroom for the main characters.

In comparison to other technologies like videoconferencing, the use of robots has not yet reached a level of adoption in the mainstream for educational or professional settings where their use has become a verb. At the time of this study, there has not been a widely adopted colloquial verb counterpart for robots like "to skype" or "zooming" [29, 30]. In the case of zooming, the adoption of Zoom software's name as a verb has been attributed to the forced exodus of learners, educators, employees, and employers to the online space during the COVID-19 pandemic which began in 2019 [31], but similar trends have not yet been reported for the use of robots.

One potential reason for the disparity in adoption of these technologies could be the technological frames possessed by individuals that shape their perception of telepresence robots, which we discuss in greater depth in the following section. On one side, videoconferencing has been frequently characterized as a cost-efficient educational tool that facilitates teaching and learning across geographical boundaries [32, 33]. On the other side, commercial telepresence robots are significantly more costly [34]. From the authors' perspectives, the direct comparison of costs does not account for the added value of telepresence robots, such as locomotion [3] and the bodily autonomy afforded by having a surrogate body [8].

\subsubsection{Applications in Educational Contexts}

The use of telepresence robots in educational settings has focused on increasing equity and accessibility. Telepresence robots have been used to help young students who suffer 
from chronic illness to attend school to gain a sense of normalcy, especially in instructor and peer relations [35-37]. The use of telepresence robots for hospitalized children has also helped facilitate students' academic progress [38]. The surrogate technological bodies can also facilitate human-human interaction. In one example, a physically present student affectionately touched their robot classmate as though they were interacting with another person [37].

Numerous exploratory studies have examined the experiences of novice operators of telepresence robots in novel settings. In the United States, there was a study of the first-time experiences of elementary and middle school children (ages 9-13) with operating telepresence robots as part of navigating obstacle courses and interacting with experimenters during simulated learning activities [39]. This study revealed how novices may need help troubleshooting technology issues, and the importance of infrastructure, such as a reliable connection to facilitate uninterrupted engagement with telepresence robots. In another exploratory study, a sample of 11-12 year old students from the United Kingdom were asked about what they thought about the Rovio and Spykee robots while they were practicing how to pilot the robots [10]. These students used the time to remotely navigate the school with their robot bodies, interact with the students in the school, and complete a scavenger hunt for cardboard stars.

Other research has reported on telepresence robot operation as a treatment condition, where researchers observed the impact of robot use. Elementary students in Australia interacted with their Japanese counterparts with robots as part of a study to examine the quality and quantity of computermediated communication between robot operators and users of videoconferencing, which revealed better engagement in the human-robot interaction condition than the humanvideoconferencing condition [40]. In another study, Japanese students (4-8 years old) used telepresence robots to interact with an English-speaking teacher as part of a storytelling exercise, and the students who operated the robots received more frequent feedback from their teacher than their counterparts who used videoconferencing [41]. Undergraduate students at a university in the Midwest region of the United States described instructors who used telepresence robots as more credible than automated robot instructors [42]. Similarly, telepresence robots have been tested as a resource for distance education, allowing remote teachers to interact with students separated by geography, such as an English teacher who used a telepresence robot to teach Korean students in small groups for two months [7]. Telepresence robots have also been tested in library contexts as a possible means to provide mobile support to students throughout the library stacks [43].

However, there are some contexts where robots have been studied under in vivo conditions, where robot implementation existed prior to the research itself and thus were not introduced as part of a manipulated treatment condition. one example of this was the the study by Lei et al. [8], which observed graduate students who used telepresence robots to remotely attend a synchronous-hybrid course and interact with their on-campus instructor and classmates, as well as other robotic classmates [8]. The institution where this research was conducted had already adopted telepresence robots for several years, and they were widely used by members of the institution. Similarly, prelicensure nursing students also used telepresence robots for clinical simulations [44, 45]. Zhang et al. reported the use of telepresence robots for remotely located teachers to give lectures in K12 settings that integrate facial recognition and directional sound and distance features [46].

\subsubsection{The COVID-19 Pandemic and Technology Innovation}

External factors may drive greater demand for telepresence robots. This has already been observed with videoconferencing and the aforementioned Zoom platform. With the COVID-19 pandemic, teaching and learning online (e.g., with use of Skype or Zoom) became the new norm. According to data reported by the United Nations Educational, Scientific and Cultural Organization, the total number of children displaced by partial or full school closures peaked at approximately 1.32 billion in June of 2020 [47]. As the number of global vaccine doses administered has reached an estimated 5.88 billion and continues to rise [48, 49], an optimistic perspective would suggest that the world as a whole can prepare for a sense of "normality." But with the prediction of future pandemics expected by experts [50], a return to more of the same challenges of delivering high-quality and engaging learning experiences to students in remote settings is widely anticipated.

Consequently, the authors believe it is important to examine how emergent technologies, like telepresence robots, can be integrated into mainstream culture. Existing technologies, like videoconferencing, are limited in their usefulness when tasks require a physical presence, which can a critical dimension of teleenablement [51]. By making progress towards integration of telepresence robots and improving the academic understanding of how operators use robots, it is possible to improve design philosophies in ways that can lead to more advanced iterations that appeal to both experienced operators and new adopters, and future proof our societies for any large-scale disruptions of day-to-day activities.

\subsection{Technological Frames}

When users approach a new technology such as telepresence robots, their actions and understanding are shaped by their technological frames. These frames are cognitive models that encompass an individual's perceptions of a technology, such 
as their assumptions, expectations, and values [52]. Consequently, these frames will shape how an individual user may conceptualize how a given technology could be used for their purposes, the conditions for its success, and the impact of its use. Technological frames have been useful for understanding the receptiveness of individuals toward care robots (also known as carebots), autonomous robots that are designed to replicate or supplement the services offered by caregivers in health and human services [53]. With data collected from focus groups consisting of 94 professional care staff, older adults, and preservice care workers, Frennert et al. reported several technological frames that contextualized the way people viewed care robots [54]. One example frame was the problematic perception of care robots as a substitute for human caregivers, which included a contrast of views associated with a quality of care that is more efficient but indifferent. While the authors did not fully delineate these frames on an individual basis, expectations of proper functioning and efficiency generally emerged from health care professionals, while concerns about dispassionate care were reported by the potential recipients of said services-further highlighting how context may shape receptiveness toward robots and other emergent technologies.

On a similar note, a stakeholder's background can be a technological frame. For example, Nielsen et al., who described the use of robot vacuums as part of elder care services, found that the actual use of the robots in assisted living facilities contrasted with home-based care [55]. In the assisted living facilities, staff viewed the robots as replacements for traditional methods of care, while home-based clients felt the robots were supplemental at best and did not perform as well as expected. In turn, when describing the perceptions of the nature and usage of robots that exist, Nielsen et al. collected a wide range of perspectives from participants, such as enthusiasm, cost-savings, concerns about quality of function, and innovation [55]. Put together, research on technological frames shows how a variety of factors can influence the perception of technology by individuals. In the present study, the authors focused on a small subset of technological frames, specifically individuals' perceptions about the usefulness, ease of use, social norms, and risks of using telepresence robots, as well as patterns across multiple stakeholder frames (e.g., students, faculty, staff).

\subsection{The Technology Acceptance Model}

One useful framework that takes into account the technological frames that influence understanding and actions toward technology is Davis et al.'s Technology Acceptance Model [18]. It is a robust framework that has been used to predict the acceptance of telepresence roots as well as other technologies, such as the use of content management and learning Management systems by faculty in higher education [56,
57], the use of computers by preservice teachers [58], and the acceptance of an online virtual game, Second Life, for the purpose of health education [59].

While Davis et al. focused on perceived usefulness and perceived ease of use for predicting use intention [18], other models, such as the TAM2 [60] and TAM 3 [61], include additional predictors like subjective norm and perceived risk, which have not been thoroughly examined in predictive models for the acceptance of telepresence robots. The primary outcome in TAM is use intention, which Davis et al. called behavioral intention to use and defined as a person's intention to use a specific technology [18]. Building upon this framework, we explored the potential of four variables to predict the use intention of telepresence robots: perceived usefulness, perceived ease of use, subjective norm, and perceived risk.

\subsection{Predictors of Telepresence Robot Acceptance}

\subsubsection{Perceived Usefulness}

In this study, we used Davis et al. (p. 985) definition of perceived usefulness as a user's perception of the "subjective probability that using a specific application system will increase his or her job performance within an organizational context" to account for all user types, such as students and staff, and all use contexts that may be part of one's job responsibilities [18]. Operators' perceptions about the usefulness of telepresence robots are a central part of the acceptance of telepresence robots.

Telepresence robots have been evaluated as useful for facilitating interaction without colocation. For student operators, this means being able to attend school remotely even when managing issues like chronic medical conditions $[9,62$, 63], short-term challenges like minor illness or suspensions [6], or a disability that may require individual modifications to traverse around school [21]. Other examples include the use of telepresence robots for assisting elderly with daily activities, which was perceived as useful by caregivers for many tasks, such as measuring vital signs and telemanipulation [11]. Mobility and tele-manipulation are also key components of making robots useful for social interactions, such as when grandparents seek to engage in long-distance interactions with (and supervision of) young grandchildren [64].

Low perceptions of usefulness are also problematic for acceptance of telepresence robots, as noted by teachers about their ability to see all of their students because of the narrow field of view offered by their robot's camera [7]. Telepresence robots are less accepted by caregivers, such as practical or registered nurses, when the robots did not serve the task intended, such as demonstrating light exercise and helping their patients with daily activities [38]. Perceived usefulness 
was found to be positively correlated with intention to use for Finnish medical care workers, a majority of whom were practical or registered nurses [13].

Perceived usefulness has been a commonly used measure for the acceptance of telepresence robots, such as by nursing students and faculty mentors participating in clinical simulations [65]. Perceived usefulness has also been measured with older adults, aged 65 and older, who operated Kubi robots in a laboratory setting [21, 65]. These capabilities have been identified as an asset for supporting language education [7] due to their ability to support operators' autonomy, their ability to control what they see, and their sense of immersion within the learning environment [23]. Perceived usefulness is generally a positive predictor of use intention [66].

Perceived usefulness also appears to have a persistent positive relationship with intention, as shown by its use in other frameworks related to TAM, such as Theory of Reasoned Action (TRA), in which perceived usefulness is positively related to use intention of online websites related to health and medicine during initial usage and after five weeks [67]. Perceived usefulness also appears to be a relatively consistent construct. In a study using TAM, measurements of expected perceived usefulness of interactive quizzes and screensharing at the start of the study were not statistically different from repeated measurements taken one semester and one year later [68].

\subsubsection{Perceived Ease of Use}

Perceived ease of use was defined by Davis et al. (p. 985) as "the degree to which the prospective user expects the target system to be free of effort" [18]. Perceived ease of use has been an important factor in previous research on the acceptance of robots. In Herring's review of multiple robot systems, they compiled a list of critical domains of features needed to ensure ease of use, which included control interface, movement abilities, audiovisual quality, and durability [21]. In particular, the importance of control interface, as highlighted by Kristoffersson et al.'s review of the literature on telepresence robots, denotes how design choices, such as touch screens, can make the operation of such robots easier [3].

The acceptance of telepresence may be low due to poor ease of use associated with the technical restrictions of the robot [69]. Telepresence robots that require too much concentration may result in low ease of use [43]. Insufficient mobility and the need for human intervention has been associated with poor perceived ease of use [21, 65]. Fitter et al. revealed that the ease of use of telepresence robots for elementary age students was impacted by the initial setup of the software needed to operate the robots as well as difficulty with troubleshooting problems [39]. Accordingly, the responsiveness of the robot system to operator input also pos- itively affects ease of use [70, 71]. The ease of use of robots also depends on its applications, as caregivers reported lower levels of ease of use for tasks such as taking vital signs for patients but higher levels for using the robot to communicate with patients [11]. Although the TAM framework shows that perceived ease of use is a positive predictor of use intention, the empirical results vary. In a sample of employees at companies with experience with telepresence systems, Park found perceived ease of use as a significant positive predictor of use intention [66]. However, perceived ease of use was not found to be a significant predictor of use intention with intention to use for Finnish medical care workers, a majority of whom were practical or registered nurses [13].

\subsubsection{Subjective Norm}

Subjective norm has been defined by Ajzen (p. 302) as a "person's perception that most people who are important to him think he should or should not perform the behavior in question" [72]. The inherently social nature of telepresence robots suggests that the social approval received by their operators from their peers may affect their future use intentions [3]. The social acceptance of a telepresence robot through perceptions of their humanness may provide operators explicit and implicit feedback about how much their use of robots is supported (i.e., social support), based on their treatment in their robotic forms. Telepresence robots in public places are treated differently based on the architecture of their bodies [73]. For instance, operators of robots with more mobility (i.e., had wheels and could move around) were afforded higher scores of deserving equal treatment, equal protection, voting rights and eligibility of election than their nonmobile counterparts (i.e., had a platform and were stationary). The anthropomorphizing of telepresence robots by the inclusion of a display of an operator's face produced longer interaction times with people than robots without such a display [74].

The TAM framework indicates that subjective norm is positively related to use intention, which is generally supported by empirical research. For Finnish care givers in the medical field, they found that subjective norm, which they referred to as social influence, was a significant positive predictor for the use intention of telepresence robots [13]. Similarly, a survey of employees from companies in 14 countries showed that subjective norm was positively predictive of use intention for telepresence systems [66]. The broad impact of subjective norm has been demonstrated in a meta-analysis, where subjective norm moderated both perceived usefulness and attitude toward use; and this effect was stronger for students than non-students, which the authors attributed to students' tendency toward compliance [75]. But the relationship between use intention and subjective norm may depend on the technology itself as the previous empirical results have varied across technologies. In a study of 
Fig. 1 A path model for the hypothesized relationships between perceived usefulness, perceived ease of use, subjective norm, perceived risk, and use intention of telepresence robots

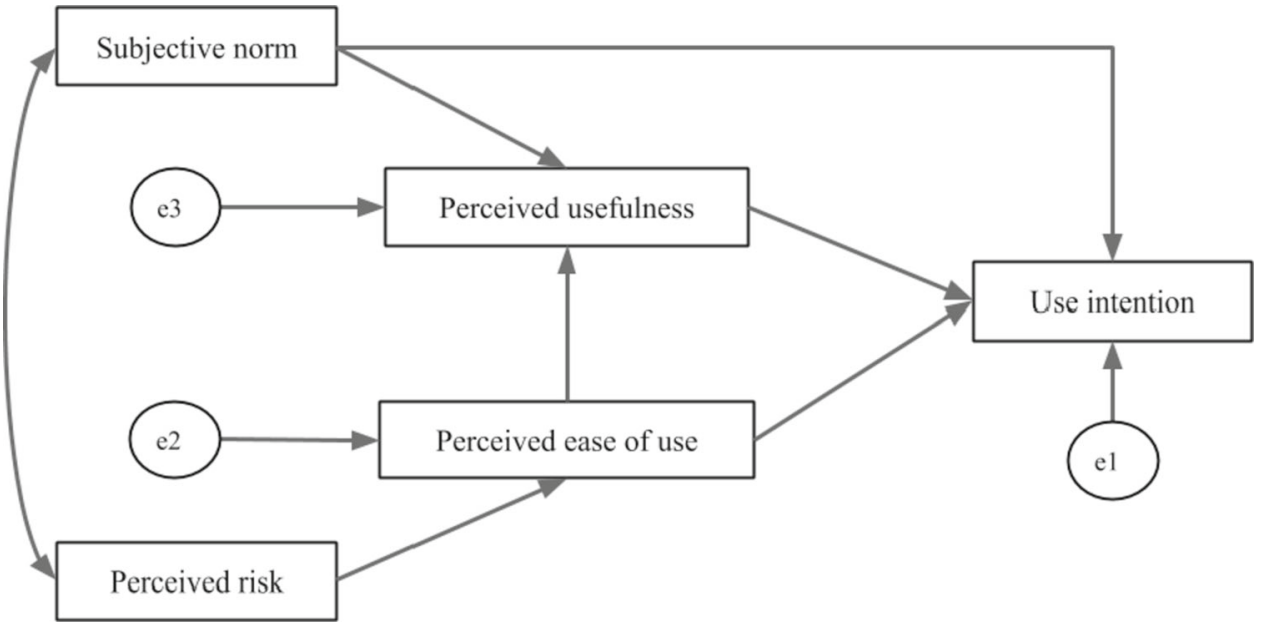

an organizational workflow program, subjective norm only positively affected use intention when technology use was mandatory but not when use was voluntary [60]. In other cases, subjective norm had a positive effect on voluntary technology use intention of social networking sites [76].

\subsubsection{Perceived Risk}

Perceived risk has been defined as the uncertainties about outcomes associated with technology use [77]. This includes the degree to which a target object will function in the way expected (performance risk), the judgement of others on their use of a target object [78], and the consistency of the use of a target object with one's self-image (psychological risk) [79]. For operators of telepresence robots, there are several specific risks associated with the social context for their use, which include the risk of being bullied [80], being a distraction for others [81-84], and social costs (e.g., embarrassment) that are related to the degree of perceived robot acceptance in the context within which a user may be operating [85]. Case studies of operators have frequently documented their concerns about their operation and technological glitches, which may reflect poorly on themselves in a manner that fosters psychological risk [86], as well as their worries about the risk of diminished autonomy due to their robot bodies being able to be shut down by others [87]. There are also risks of being socially excluded or unaccepted [88], as well as being ignored or being relegated behind physically present peers [69]. Operators have reported concerns about being a distraction, as well as elation when their robot use was not disruptive [83, 89, 90].

Prior research for self-service banking technologies demonstrated that perceived risk negatively affected perceived ease of use and perceived usefulness [91]; neither perceived ease of use nor usefulness were significant predictors of use intention in that setting. In contrast, another study found that perceived performance risk involving the use of social networking sites was positively associated with perceived ease of use, which they attributed to users' level of understanding [92]. Specifically, those who demonstrate greater understanding of the technologies' potentials, as manifested by perceived ease of use, are also more aware of the risks - in a manner that could positively impact use intention for social networking sites. However, these relationships have not been explored with telepresence robots.

\subsection{Research Question and Hypotheses}

In this study, we sought to answer the question: how do perceived usefulness, perceived ease of use, perceived risk, and subjective norm affect the use intention of telepresence robots of operators in ecologically valid educational settings? Based on the prior research and the Technology Acceptance Model, we constructed the hypothesized Acceptance of Telepresence Robots (ACTRS) model shown in Fig. 1, in order to test the following hypotheses:

- Hypothesis 1: Perceived usefulness will have a significant positive effect on use intention.

- Hypothesis 2: Perceived ease of use will have a significant positive effect on use intention.

- Hypothesis 3: Subjective norm will have a significant positive effect on perceived usefulness and a significant positive effect on use intention.

- Hypothesis 4: Perceived risk will have a significant negative effect on perceived ease of use. 


\section{Materials and Methods}

\subsection{Data Collection Procedure}

Data for this study was collected using an online survey with the platform Qualtrics. A link to the survey was distributed to an initial pool of 284 registered users of the telepresence robots at our study site, a large research university in the Midwest region of the United States of America. To all nonrespondents, except for people who opted out of receiving email notifications, we sent two additional reminders to participate in the survey.

\subsection{Instrument}

For this study, we designed a scale for telepresence robots to measure use intention, perceived usefulness, perceived ease of use, subjective norm, and perceived risk based on existing scales (for the full scale and reliability analysis, see Appendix A). The items for perceived usefulness and perceived usefulness were adapted from Davis et al.'s initial work [18], using another study that cited Davis et al. as a model [70]. The items for use intention were adapted from Teo's study [93]. The items for subjective norm items were adapted from TAM2 [60]. The items for perceived risk were adapted from prior studies [76, 94]. All responses were recorded on a 7-point Likert scale.

The factor loadings for our indicators were generally between good (>0.55) and excellent $(>0.71)$, with the exception of the third indicator for subjective norm, which had a weak loading, and the third indicator for perceived risk, which had a poor loading [95]. The Cronbach's alpha for perceived usefulness, perceived ease of use, and use intention exceeded the general reference value of 0.80 [96]. The subscales for subjective norm and perceived risk were near to the $>0.60$ and 0.70 range used as reference points for minimum acceptable reliability for exploratory studies [97-100]. Consequently, the factor loadings and reliability data suggest the instrument in this study was adequate but could be improved.

\subsection{Sample}

Through purposive sampling at a study site where telepresence robots were regularly used by students, faculty, and staff, we obtained an initial sample of 72 responses, but 12 cases were excluded from the final analysis. Out of these dozen excluded cases, nine were omitted because the participants started the survey but did not input any data. The other three cases were omitted because the data was too incomplete for item-level substitution. Specifically, if nonresponse was observed for more than a majority of the measurement items for any construct, then responses were marked as incomplete and invalid at the case level. For example, the measure of perceived usefulness included four indicators, and if nonresponse was observed for more than two indicators, then mean substitution was not applied.

Mean substitution was used to manage missing data in this sample due to its emergence as an appropriate method for estimating values likely to represent the individual based on their response to other indicators [101]. This resulted in a sample of 60 respondents, which produced an effective response rate of $21.1 \%$; and within the sample, mean itemlevel substitution was used for three of the respondents.

This sample of 60 respondents included faculty, students, and professionals (e.g., staff, visiting professionals) (see Table 1). These respondents represented experience with a variety of telepresence robots, including Double, Kubi, Beam, and Beam Pro. Examples of individuals from the category of "other professionals" included users who self-identified as alumni, academic staff, and visiting professionals. Our sample used the robots for diverse classroom needs, which included teaching and learning in the classroom, as well as for collaborative purposes, such as research meetings, interviews, and study sessions. A majority of the sample was experienced, having used telepresence robots for at least a couple months. For our path analysis, the sample size was adequate based on the 5:1 reference ratio of sample to parameter [102, 103].

Although the sample includes a mix of experienced and inexperienced users, about $75 \%$ had at least a couple months of experience using the robot $(N=45)$. This predominance of experienced users afforded multiple benefits to the data collection. To begin, building off prior research, recognition of long-term consequences is a significant predictor of personal computer use for experienced users but not for inexperienced users, and users with more experience are not influenced by feelings toward personal computers in the same manner that inexperienced users are [104]. Second, the recruitment of experienced operators also gives a more accurate measurement of acceptance of technology, since perceptions of ease of use vary over time between experienced and inexperienced users. For instance, inexperienced users show an initial learning curve, where their perceptions of the ease of use starts low before increasing with training, nearing the perceived levels of ease of use of experienced users [105].

Overall, because prior research demonstrates that inexperienced users have differing initial experiences in terms of technology acceptance, the use of a sample of experienced users eliminates this "novice effect," which gives a more accurate picture of long-term technology acceptance. Conversely, acceptance data with novice operators changes over time, so cross-sectional data would be limited in its generalizability across time. The authors do acknowledge that part of the design process is optimizing the learning curve of 
Table 1 This table shows the sample demographics, which includes the age brackets of users, their roles at the sample site, their length of use, and the contexts for their use

\begin{tabular}{lrlrlrr}
\hline Age & N & Role & N & Length of use & N & Use context \\
\hline $18-24$ & 1 & Students & 33 & A couple days & 12 & Classroom use \\
$25-44$ & 40 & Faculty & 16 & A couple weeks & 2 & Collaborative use \\
$45-64$ & 18 & Both & 1 & A couple months & 10 & Other \\
No response & 1 & Other & 9 & Around a year & 9 & \\
& & No response & 1 & More than a year & 26 & \\
& & & No response & 1 & \\
\hline
\end{tabular}

Participants were allowed to identify more than one "use context", which explains why that category totals more than the sample size $(N=60)$

adopting a new technology; however, the issue of onboarding for new users is beyond the scope of the present study.

\subsection{Preliminary Data Analysis Procedure}

We tested for normality by using the Shapiro-Wilks test, which is appropriate for modest sample sizes [106], calculating and comparing the observed kurtosis and observed skewness with the reference values for kurtosis $(-1.5<\mathrm{ks}<1.5)$ and skewness $(-1<\mathrm{sk}<1)$ [107], and evaluating the histograms of the data distributions. We calculated standardized z-scores to identify outlying data, using the cut-off of values of $|z|>3$. Traditionally, for nonnormal data, transformations have been recommended to approximate a normal distribution in prior research [108-110], since transformations can bring about normality in the data, minimize the influence of extreme values on the dataset, and potentially improve the power of parametric analyses [111, 112]. However, a drawback of transformations is the increased difficulty of interpretation of the relationships between the independent and dependent variables [113]. Even further, in the present study, data transformations did not improve the normality of the distribution. Because of these factors, the analyses were conducted with nontransformed data. For our instrument reliability, we conducted confirmatory factor analysis using maximum likelihood estimation, and calculated the Cronbach alpha for each of the five subscales.

\subsection{Model Testing Procedure}

An important preliminary step in path analysis and structural equation modeling is the assessment of model fit, which is the determination of whether or not the theorized relationships between variables accurately reflects the data collected and phenomenon being studied [114]. To test the model fit, we calculated several commonly used indices, which included $\mathrm{CMIN/df}$ and associated significance, Tucker Lewis Index (TLI), Comparative Fit Index (CFI), Normed Fit Index (NFI), and root mean square error of approximation (RMSEA) [114].
Table 2 This table shows the observed values for the goodness-of-fit indices used to evaluate the hypothesized ACTRS Model shown in Fig. 1

\begin{tabular}{llllllll}
\hline Model & CMIN & df & Sig & NFI & TLI & CFI & RMSEA \\
\hline ACTRS & 3.770 & 3 & $p<.287$ & .940 & .951 & .985 & .066 \\
\hline
\end{tabular}

We used path analysis to test the direct and indirect effects of the four predictors relevant for our study (perceived usefulness, perceived ease of use, subjective norm, perceived risk) on use intention. Path estimates were generated using the maximum likelihood estimation method, with bias-corrected bootstrapping with 1000 samples and confidence intervals at the $\mathrm{CI}=95 \%$ level [115]. All structural equation modeling was completed with SPSS 25 Amos 6 software.

\section{Results}

\subsection{Outliers}

No outliers were identified in our dataset.

\subsection{Normality of the Data}

However, the data for several of our variables (i.e., perceived ease of use, use intention, and perceived risk) violated assumptions of normality based on the observed significance of test statistics for the Shapiro-Wilks test for these variables. Further inspection of the skewness and kurtosis values for our variables suggested the data were normal except for perceived ease of use, which had a kurtosis value of 6.661 and a skewness of -2.117 , which were beyond the cut-off values for kurtosis and skewness to indicate normality. However, high values of kurtosis appear to be manageable, as prior social science research has been able to proceed with structural equation modeling even when isolated high kurtosis values were present [116]. Nonnormality was also suggested by visual examination of the histograms. 
Table 3 This table shows the descriptive statistics and correlations of perceived usefulness, perceived ease of use, subjective norm, perceived risk, and use intention from the ACTRS Model

\begin{tabular}{llllll}
\hline Variables & 1 & 2 & 3 & 4 & 5 \\
\hline Perceived usefulness & - & & & & \\
Perceived ease of use & $0.357^{* *}$ & - & & \\
Subjective norm & $0.552^{* *}$ & 0.142 & - & & \\
Perceived risk & $-0.319^{*}$ & $-0.272^{*}$ & -0.158 & - & \\
Use intention & $0.520^{* *}$ & $0.354^{* *}$ & $0.429 * *$ & -0.137 & - \\
$M$ & 5.071 & 6.144 & 4.894 & 4.167 & 5.689 \\
$S D$ & 1.022 & 0.927 & 1.119 & 1.365 & 1.206 \\
Minimum & 2.250 & 2.000 & 2.000 & 1.000 & 2.333 \\
Maximum & 6.750 & 7.000 & 7.000 & 7.000 & 7.000 \\
Skew & -0.276 & -2.117 & -0.302 & -0.654 & -0.901 \\
Skew S.E & 0.309 & 0.309 & 0.309 & 0.309 & 0.309 \\
Kurtosis & -0.162 & 6.661 & 0.100 & 0.301 & 0.203 \\
Kurtosis S.E & 0.608 & 0.608 & 0.608 & 0.608 & 0.608 \\
Valid N & 60 & 60 & 60 & 60 & 60 \\
\hline
\end{tabular}

${ }^{*} p<.05, * * p<.01$ (two-tailed)

Table 4 This table shows the unstandardized and standardized path coefficients for the paths tested in the ACTRS Model shown in Fig. 1

\begin{tabular}{|c|c|c|c|c|}
\hline Path & Unstandardized coefficient & Standardized coefficient & SE & Sig. (two-tailed) \\
\hline Perceived Ease of Use $\rightarrow$ Use Intention & .269 & .209 & .147 & $p<.067$ \\
\hline Perceived Usefulness $\rightarrow$ Use Intention & .383 & .324 & .159 & $p<.016$ \\
\hline Subjective Norm $\rightarrow$ Use Intention & .237 & .223 & .136 & $p<.082$ \\
\hline Perceived Ease of Use $\rightarrow$ Perceived Usefulness & .313 & .289 & .113 & $p<.005$ \\
\hline Subjective Norm $\rightarrow$ Perceived Usefulness & .468 & .520 & .093 & $p<.001$ \\
\hline Perceived Risk $\rightarrow$ Perceived Ease of Use & -.185 & -.272 & .085 & $p<.030$ \\
\hline
\end{tabular}

As a result, we attempted several data transformations, including square root, $\log 10$, and inverse transformations as described in our methods. However, as mentioned before, these transformations exacerbated the nonnormality and failed to generate approximations that were closer to that of a normal distribution. This finding was in line with prior research noting that data transformations of nonnormal distributions is not always successful [117]. Fortunately, the maximum likelihood estimation method in structural equation modeling is robust even in situations involving nonnormality in data [118].

\subsection{Goodness of Model Fit}

An analysis of the fit indices indicated that the hypothesized relationships between the variables in the ACTRS model accurately described the data collected from our sample. This goodness of fit was determined with several indices as described in the procedure (see Table 2). For good model fit, we sought a nonsignificant $p$ value for CMIN/df, TLI $>0.95$ [119, 120]; CFI >0.95 [120]; NFI >0.90 [121]; and RMSEA $\leq 0.08[122,123]$. There were no significant covariances between subjective norm and perceived risk $(B$
$=-0.238$, S.E. $=0.189, p<0.229)$. Overall, the results of our fit analyses suggested that the ACTRS Model was a good fit for our data. Descriptive statistics for the ACTRS Model are presented in Table 3. Path estimates for the ACTRS Model are presented in Table 4.

\subsection{Hypothesized Model Paths}

- Hypothesis 1 was supported. Perceived usefulness had significant had a significant positive effect on use intention.

- Hypothesis 2 was not supported. Perceived ease of use did not have a significant positive effect on use intention.

- Hypothesis 3 was partially supported. Subjective norm had a significant positive effect on perceived usefulness but did not have a significant effect on use intention.

- Hypothesis 4 was supported. Perceived risk had a significant negative effect on perceived ease of use.

Hypothesis 1 was supported by our findings, such that perceived usefulness was found to have a significant, direct positive effect on use intention, where the unstandardized path coefficients indicated that a one unit change in perceived 
ease of use was related to a 0.383 unit change in use intention on the seven-point scale $(\mathrm{p}<0.016)$.

Hypothesis 2 was not supported as the path coefficient for Perceived Ease of Use $\rightarrow$ Use Intention was not statistically significant $(\mathrm{p}<0.067)$. This finding indicated that the ease of use of telepresence robots did not directly affect operators' intentions to use the robots.

Hypothesis 3 was partially supported, such that subjective norm was found to have a significant, direct positive effect on perceived usefulness, where the unstandardized path coefficients indicated that a one unit change in subjective norm was related to a 0.468 unit change in perceived usefulness $(p<.005)$. However, the path coefficient for Subjective Norm $\rightarrow$ Use Intention was not statistically significant $(\mathrm{p}<0.082)$, which indicated that subjective norm did not directly influence use intention of telepresence robots. Subjective norm did have a significant indirect positive effect $(B$ $=0.179, p<0.003$ ) on use intention, mediated by perceived usefulness. In the traditional structural equation modeling approach described by Baron and Kenny [90], this indirect effect may only be considered if the Subjective Norm $\rightarrow$ Use Intention path was significant; however, the work of MacKinnon et al. [124] has shown that this approach exhibits low power and high Type I error rates. As such, following MacKinnon et al. [115], we may interpret the results of our study to show that perceived usefulness is a partial mediator for subjective norm's indirect effect on use intention, and for perceived ease of use's indirect effect on use intention.

Hypothesis 4 was supported by our findings, such that perceived risk was found to have a significant, negative effect on perceived ease of use, where the unstandardized path coefficients indicated that a one unit change in perceived risk was related to a -0.185 unit change in perceived ease of use.

\section{Discussion}

\subsection{Overview of Findings}

- Operators are more likely to continue using telepresence robots if they think telepresence robots are useful.

- How easy or difficult it is to use telepresence robots affects operators' perceptions about the usefulness of telepresence robots.

- Social pressure to use telepresence robots affects operators' perceptions about the usefulness of telepresence robots.

- The perceived risk of using telepresence robots affects operators' sense of their ease of use.

\subsection{It is Important that Telepresence Robots are Seen as Useful}

The results of this study demonstrated that the primary direct influence on use intention of telepresence robots in educational contexts is how much an operator perceives the robots to be useful for their purposes. This finding is consistent with general research that has shown perceived usefulness to be a strong, long-term predictor of use intention of technology [125], and prior research that has shown this same relationship in telepresence contexts [13].

The authors posit that the central influence of perceived usefulness may be explained by Achievement Goal Theory, a theory that explains the motivation for behavior as a result of the desire to demonstrate or improve one's skills within a specific situation [126, 127]. Consequently, when an individual views telepresence robots a potentially useful in helping them to advance these goals, then they will be motivated to use the platform.

\subsection{The Ease of Use of Telepresence Only Matters if It Affects Usefulness}

One explanation for the influence of perceived ease of use on the usefulness of telepresence robots may be attributed to their complexity and the cognitive load demands for their operation. Telepresence robots are a complex aggregate of multiple technological and human components, and the relationships of these components are central to defining the system [128]. As described in the introduction, telepresence robots include a videoconferencing component, which allows an operator to see and hear, as well as to be seen and heard by others in a remote location. This relies on several infrastructure components, such as a team who delivers and configures the robots to the remote location, which includes charging the robot battery and setting up the internet connection. The successful operation of the telepresence robot also depends on the responsiveness of the human other, such as if they respect the bodily autonomy of the robot, or instead try to mute or move the robot when they are viewed as a disturbance (something a person would likely not do to another physically embodied person). Moreover, the operation of the telepresence robot usually involves a control software that must be installed on some hardware for the operators, both of which will need to be maintained. This includes configuring the device, such as setting up internet connections and appropriate permissions, as well as the installation and continuous updating of control software for the robot, which may have to be completed by the operator themselves or by an information technology team.

The complexity of telepresence robots also presents cognitive load challenges, which is the result of the finite amount of working memory available for a person to process stim- 
uli [129]. The operation of telepresence robots places a high demand for cognitive resources. For example, moving from a space that is quiet to one that is noisy will require the operator to modify their microphone configuration so they can be heard in the new space. While operators are on the move with their robots, they may use multiple cameras, such as on the Beam Pro, in order to see their surroundings. Operators must account for environmental conditions, such as being conscious of areas that may have an internet dead zone and the locations of accessible ramps. Operators must also be skilled with their input devices, whether they are using a computer keyboard and/or mouse, a touch screen, or a video game controller. They may also have to juggle manipulating their robot and observing social etiquette, such as appropriate social distance and maintaining eye contact during social interactions.

Ultimately, the difficulty of operating telepresence robots may not affect decisions for their use so long as it does not cross a threshold where the difficulty of operation begins to impact the robots' usefulness. Therefore, it is important that the user interface is designed for minimal barrier of entry for operators, and there should be unburdensome infrastructure needs (e.g., set-up, maintenance) to ensure that the ease of use stays below this critical threshold.

\subsection{Social Pressure Does Affect Perceptions About the Usefulness of Telepresence Robots}

The results for the subjective norm paths indicate that positive social support can increase operators' perceptions of the usefulness of telepresence robots. These results contrast with prior work that has demonstrated a direct effect of subjective norm on use intention for telepresence systems [66], use intention for telepresence robots [130], and intention to work with social robots [131]. In one example, the pooled data from four studies has shown significant relationships between subjective norm and use intention, and subjective norm and perceived usefulness [60]. Although we only observed the positive direct effect of subjective norm on perceived usefulness, our results were also consistent with a prior study that used the TAM framework to measure students' perceived usefulness of e-portfolios [132].

This relationship may also be explained by the environment of the study site, where the use of telepresence robots had been normalized and generally encouraged by members of the university. It is likely this social background has shaped the statistically significant relationship between subjective norm and perceived usefulness in this particular study.

\subsection{Perceived Risk Can Affect Perceptions About the Ease or Difficulty of Using Telepresence Robots}

The findings of this study suggest that perceived risk has a significant negative effect on the perceived ease of use of telepresence robots, which differs from prior studies. For example, Lu et al.'s [133] study on the acceptance of antivirus software reported that perceived risk had a significant effect on perceived usefulness but not perceived ease of use, and perceived usefulness was a significant predictor of use intention but not perceived ease of use. While we did not test moderation, the significant direct effect of perceived risk on perceived ease of use was consistent with prior work on the acceptance of other technologies, like websites, which posit that when perceived risk is high, the usability of technology becomes more important [134]. As described in the introduction, operators are often concerned about the social risks associated with the use of telepresence robots, which would be consistent with these findings.

\section{Conclusion}

\subsection{Usefulness as a Core Factor in Telepresence Robot Design}

The ACTRS Model indicates that usefulness needs to be prioritized in the design of telepresence robots. At the institution level, the deployment of commercially available platforms will depend on identifying congruity between the features available in their design and the functional demands of the robots in the settings where they will be used. For example, if a lot of human-robot interaction will be a part of their implementation, then the aspect of robot anatomy may be important. As described in Sect. 1.1.1., the portability of small telepresence robots may produce awkwardness for individuals as they may have to assume uncomfortable positions to interact with the operators using the robots. Therefore, it would be important to involve all stakeholders, such as students, educators, and administrators, to identify the expected functions and to evaluate how well commercial offerings can meet the conditions needed to ensure high acceptance after deployment.

In the case of noncommercial telepresence robots, the process should begin with the identification of the expected functions needed of the telepresence robots, followed by a determination of how to best make those functions a possibility in the prototype or final robot design. 


\subsection{Simplify Designs and Minimize Cognitive Load Demands}

The influence of perceived ease of use on perceived usefulness indicates that telepresence robot designs need to minimize complexity and cognitive load demands as much as possible. Future designs of telepresence robots must optimize the end user experience so that the operator can dedicate their cognitive resources to completing tasks with their telepresence robots, rather than controlling the robot itself.

In order to achieve this kind of optimized design, the authors believe telepresence robots should emphasize specialization rather than universality. The recognition of diverse needs is an important philosophical position across all dimensions of creating a more welcoming and inclusive society, but more especially when examining our teaching and learning practices. And just as no one instructional strategy would be effective for all learners, it is also unlikely that a single telepresence robot platform would be able to satisfy the intended use(s) for all operators. In this sense, a modular approach to telepresence robot design (resulting from the convergence of multiple design ideas) could allow for the development of robots configured for specific teaching and learning goals, in a manner that is more compatible with the varied frames that shape people's perceptions of the robots.

Such specialization also reflects the goal of culturally responsive technology design, an extension proposed by the authors, that is based on prior concepts such as culturally responsive teaching and culturally responsive design. Culturally responsive teaching emphasizes the use of instructional practices that recognize and support the cultural diversity of learners [135], while culturally responsive design promotes the development of broader learning environments that focus on the same goals [136]. In this sense, a deeper consideration of cultural differences would likely provide further insights into what might make telepresence robots easy to use for users. For example, East-West differences in the acceptance of human-like robots (e.g., greater acceptance in Japan) has been attributed to the presence of an Eastern value system that focuses on making robots that are "harmonious" with humanity rather than fixating on human-robot differences in a manner that is typically observed in Western countries (Kaplan, p. 470) [137]. Similarly, regional differences in perceptions of humanoid robots have been observed between individuals from African countries (e.g., Egypt, Sudan) and countries from The Gulf (e.g., Iran, Saudi Arabia), with the latter reported as holding more favorable views toward robots [138].

Telepresence robots with modular designs that allow specialization of function can also support usefulness by facilitating identity presentation. In fact, users have already begun to personalize their robots to reflect their identities, such as donning them with hats and shirts [139]. However, social challenges lie ahead for the reception of robots. For instance, prior research has shown that robots with Asian or Black racial identities are perceived more negatively than their White counterparts [140]. And in another study, a female robot (cued by researchers as a robot with long hair) was given more stereotypical feminine traits (e.g., delicate, friendly) and feminine tasks (e.g., childcare, preparing meals) than the male robot (cued as a robot with short hair) [141].

Thus, acknowledgement of diverse technological frames necessitates design decisions that are responsive to the diverse backgrounds of users, while also being equitable and respectful of the multidimensionality and intersectionality of identity without reducing groups to monoliths.

\subsection{Integrating Multiple Forms of Embodiment}

The design of telepresence robots that will garner rapid, widespread acceptance in the future may also depend on the ability of those robots' platforms to integrate with other forms of embodiment. Other formats include digital self-representations, such as avatars and virtual selfrepresentations, which has been linked to student behavior, such as students who use an avatar to represent their "ideal self" being more active in online discussions [142, 143]. Users may also have three dimensional self-representations in virtual world games, which is linked to cognition [144]. These different platforms also present their own challenges to technology acceptance. In prior research, bullying has been reported when observing operators of telepresence robots [80]. Similarly, bullying has been identified in online games with virtual embodiment, such as World of Warcraft [145] and Call of Duty [146, 147].

The concept of dual embodiment in virtual and physical spaces has been described by Mavridis et al. [148], who studied the use of an "ultra-social robotic being" that could interact with humans online through Facebook chat and faceto-face with a robot body. This kind of dual embodiment can also be seen in the study by Lei et al. [8], where the students and instructors interacted on their course website and in the physical classroom with telepresence robots.

Telepresence robots may be useful as part of multiple forms embodiment by addressing prior issues in online education by giving students a more tangible sense of self. This can help offset the problem of the "faceless student" phenomenon used to describe interactions in online course discussions [149]. Additional layers of embodiment may present a multidimensional version of oneself, which may improve the quality of interactions; however, this may also present additional burdens for the ease of use due to increased cognitive load of managing multiple embodiments.

The transition between telepresence and other forms of embodiment may present a challenge to what the authors 
consider bodily continuity, which can be defined as their perception of a single, unbroken sense of self across different forms of embodiment. Therefore, the acceptance of technology, such as telepresence robots and other platforms, may also depend on the total usefulness and ease of use of each individual platform, as well as the usefulness and ease of using those platforms in combination. In line with these considerations of usefulness and ease of use, there are also concerns related to social support, given that prior research has indicated that multitasking has emerged as a result of conformity to social expectations of being constantly connected [150]. Altogether, this suggests that an important part of telepresence design in the future may be its ability to integrate with other platforms to support bodily continuity.

\section{Limitations and Future Research}

As described in our literature review, perceived risk has been operationalized with many subfactors. Consequently, one potential limitation of this study is its emphasis on performance and psychological risk. Therefore, it is unclear how other types of perceived risk may impact the perceptions of the usefulness and ease of use of telepresence robots, as well as use intention. The next step in this work would be to expand the model to include other types of risk to increase the representativeness of the construct of perceived risk, such as risk of time loss, personal harm, and financial loss [151]. Second, there may be alternative pathways that predict the use intention of telepresence robots based on prior research on technology acceptance. Some work has shown a significant negative effect of perceived risk on use intention [152]. Other studies have observed a negative effect of perceived risk on perceived usefulness [153]. In contrast, Faqih found that perceived risk had no effect on either perceived usefulness or perceived ease of use [154]. However, the comparison of multiple models was beyond the scope of the exploratory nature of the present study but may be explored in future work.

Technological frames encompass a broad range of cognitive, affective, and behavioral components, as well as personal background characteristics. The use of the Technology Acceptance Model framework in the present study provided a foundation about the general views of educators, students, and professionals toward telepresence robots in educational contexts. Specifically, the findings indicate that general views about their usefulness is the central predictor of operators' intention to use telepresence robots. Additional work is needed to examine how other aspects of technological frames are related to the acceptance of telepresence robots.

There are several aspects of the technological frames espoused by operators that should be examined in the future but were beyond the scope of the present study. First, there are the factors described in extensions of Davis et al.'s [16] Technology Acceptance Model, such as job relevance and self-efficacy beliefs from TAM 2 [31] and TAM 3 [32]. Second, future research should examine participants' unique perceptions toward each of the individual robot platforms themselves, which varied in physical structure and capabilities in the present study. For instance, the Kubi was smaller and less mobile than the Beam Pro. Third, there should be an examination of the potential influence of the stakeholder background and use context as part of technological frames toward telepresence robots (e.g., students vs faculty; interviews vs. attending class).

The authors were not able to manipulate telepresence robot use as an independent variable, so it was not possible to conduct a longitudinal examination of how views of telepresence robots changed over time as novice operators acquired more expertise. The use of pre-post study design in future research would provide a better understanding of the learning curve for the transition from novice to experienced operator, as well as the factors that predict the acceptance of telepresence robots by novice users. These kinds of results would also be valuable to inform the design of telepresence robots that can meet the expectations of usefulness for experienced users and provide a short learning curve that maximizes adoption by inexperienced users.

As an exploratory research study, this work aimed to test the validity and utility of the Technology Acceptance Model, namely by utilizing quantitative data to determine if the Hypothesized relationships would be observed in a sample of diverse telepresence robot operators. Follow-up research that utilizes a qualitative-dominant or a mixed methods approach would be useful to advance understanding regarding the acceptance of telepresence robots in any of the aforementioned areas within this section.

Data Availability Statement The datasets generated and/or analyzed during the current study are available from the corresponding author on reasonable request.

\section{References}

1. Desai M, Tsui KM, Yanco HA, Uhlik C (2011) Essential features of telepresence robots. In: 2011 IEEE conference on technologies for practical robot applications. IEEE, Woburn, MA, USA, pp $15-20$

2. Jouppi NP (2002) First steps towards mutually-immersive mobile telepresence. In: Proceedings of the 2002 ACM conference on computer supported cooperative work. Association for Computing Machinery, New Orleans, LA

3. Kristoffersson A, Coradeschi S, Loutfi A (2013) A review of mobile robotic telepresence. Adv Human-Comput Interact 2013:1-17. https://doi.org/10.1155/2013/902316

4. Guth L, Vander Meer P (2017) Telepresence robotics in an academic library: A study of exposure and adaptation among patrons 
and employees. LHT 35:408-420. https://doi.org/10.1108/LHT03-2017-0059

5. Park SJ, Han JH, Kang BH, Shin KC (2011) Teaching assistant robot, ROBOSEM, in English class and practical issues for its diffusion. In: Advanced robotics and its social impacts. IEEE, Menlo Park, CA, USA, pp 8-11

6. Cha E, Greczek J, Song A, Mataric MJ (2017) My classroom robot: Exploring telepresence for K-12 education in a virtual environment. 2017 26th IEEE international symposium on robot and human interactive communication (RO-MAN). IEEE, Lisbon, pp 689-695

7. Kwon O-H, Koo S-Y, Kim Y-G, Kwon D-S (2010) Telepresence robot system for English tutoring. In: 2010 IEEE workshop on advanced robotics and its social impacts. IEEE, Seoul, Korea (South), pp 152-155

8. Lei M, Clemente IM, Hu Y (2019) Student in the shell: The robotic body and student engagement. Comput Educ 130:59-80. https:// doi.org/10.1016/j.compedu.2018.11.008

9. Newhart VA, Olson JS (2017) My student is a robot: How schools manage telepresence experiences for students. In: Proceedings of the $2017 \mathrm{CHI}$ conference on human factors in computing systems - CHI '17. ACM Press, Denver, Colorado, USA, pp 342-347

10. Sheehy K, Green AA (2011) Beaming children where they cannot go: telepresence robots and inclusive education: an exploratory study. Ubiquit Learn Int J 3:135-146. https://doi.org/10.18848/ 1835-9795/CGP/v03i01/40261

11. Koceski S, Koceska N (2016) Evaluation of an assistive telepresence robot for elderly healthcare. J Med Syst 40:1-7. https://doi. org/10.1007/s10916-016-0481-x

12. Latikka R, Turja T, Oksanen A (2019) Self-efficacy and acceptance of robots. Comput Hum Behav 93:157-163. https://doi.org/ 10.1016/j.chb.2018.12.017

13. Turja T, Aaltonen I, Taipale S, Oksanen A (2020) Robot acceptance model for care (RAM-care): a principled approach to the intention to use care robots. Inf Manage 57:1-9. https://doi.org/ 10.1016/j.im.2019.103220

14. Kristoffersson A, Coradeschi S, Loutfi A, Severinson-Eklundh K (2011) An exploratory study of health professionals' attitudes about robotic telepresence technology. J Technol Hum Serv 29:263-283. https://doi.org/10.1080/15228835.2011.639509

15. Cesta A, Cortellessa G, Orlandini A, Tiberio L (2016) Long-term evaluation of a telepresence robot for the elderly: methodology and ecological case study. Int J Soc Robotics 8:421-441. https:// doi.org/10.1007/s12369-016-0337-z

16. Radmard S, Moon AJ, Croft EA (2015) Interface design and usability analysis for a robotic telepresence platform. In: 2015 24th IEEE international symposium on robot and human interactive communication (RO-MAN). IEEE, Kobe, Japan, pp 511-516

17. Tsui KM, Yanco HA (2013) Design challenges and guidelines for social interaction using mobile telepresence robots. Rev Human Fact Ergon 9:227-301. https://doi.org/10.1177/ $1557234 X 13502462$

18. Davis FD, Bagozzi RP, Warshaw PR (1989) User acceptance of computer technology: a comparison of two theoretical models. Manage Sci 35:982-1003. https://doi.org/10.1287/mnsc.35.8.982

19. Razzouk R, Shute V (2012) What is design thinking and why is it important? Rev Educ Res 82:330-348. https://doi.org/10.3102/ 0034654312457429

20. McGinn C, Bourke E, Murtagh A et al (2020) Meet Stevie: a socially assistive robot developed through application of a 'design-thinking' approach. J Intell Robot Syst 98:39-58. https:// doi.org/10.1007/s10846-019-01051-9

21. Herring SC (2013) Telepresence robots for academics. In: Proceedings of the American society for information science and technology. pp 1-4

22. Dim F (2019) Romo, the iPhone robot, is back! Medium
23. Liao J, Lu X (2018) Exploring the affordances of telepresence robots in foreign language learning. Lang Learn 22:20-32

24. White House (2015) President Obama greets Alice Wong via robot. https://obamawhitehouse.archives.gov/photos-and-video/ photo/2015/07/president-obama-greets-alice-wong-robot

25. Harrington R (2015) Robot visits White house. Popular Science

26. Lapowsky I, Souza P (2015) The president is now taking robot visitors. WIRED

27. Schrab R (2015) Law of robotics and party rights. Community

28. McCarthy-Miller B (2018) The snowplow. The Good Place

29. Cole J (2020) Googling, Ubering and Xeroxing: How Zooming became a verb in six months. In: Center for the Digital Future: Illuminating What's Next. https://www.digitalcenter.org/ columns/zooming/

30. Warren T (2020) Microsoft's Skype struggles have created a Zoom moment. https://www.theverge.com/2020/3/31/21200844/ microsoft-skype-zoom-houseparty-coronavirus-pandemicusage-growth-competition

31. Adedoyin OB, Soykan E (2020) Covid-19 pandemic and online learning: The challenges and opportunities. Interact Learn Environ. https://doi.org/10.1080/10494820.2020.1813180

32. Gillies D (2008) Student perspectives on videoconferencing in teacher education at a distance. Distance Educ 29:107-118. https://doi.org/10.1080/01587910802004878

33. Lawson T, Comber C, Gage J, Cullum-Hanshaw A (2010) Images of the future for education? Videoconferencing: a literature review. Technol Pedagog Educ 19:295-314. https://doi.org/10. 1080/1475939X.2010.513761

34. Rinfret SR (2020) Telepresence robots: a new model for public administration course delivery. J Public Affairs Educ 26:380-390. https://doi.org/10.1080/15236803.2020.1744798

35. Newhart VA, Warschauer M, Sender L (2016) Virtual inclusion via telepresence robots in the classroom: an exploratory case study. Int J Technol Learn 23:9-25. https://doi.org/10.18848/2327-0144/ CGP/v23i04/9-25

36. Page A, Charteris J, Berman J (2020) Telepresence robot use for children with chronic illness in Australian schools: a scoping review and thematic analysis. Int J Soc Robotics. https://doi. org/10.1007/s12369-020-00714-0

37. Weibel M, Nielsen MKF, Topperzer MK et al (2019) Back to school with telepresence robot technology: a qualitative pilot study about how telepresence robots help school-aged children and adolescents with cancer to remain socially and academically connected with their school classes during treatment. Nurs Open 7:988-997. https://doi.org/10.1002/nop2.471

38. Weiss PL, (Tamar), Whiteley CP, Treviranus J, Fels DI, (2001) PEBBLES: a personal technology for meeting educational, social and emotional needs of hospitalised children. Pers Ubiquit Comput 5:157-168. https://doi.org/10.1007/s007790170006

39. Fitter NT, Chowdhury Y, Cha E et al (2018) Evaluating the effects of personalized appearance on telepresence robots for education. Companion of the 2018 ACM/IEEE international conference on human-robot interaction. ACM, Chicago IL USA, pp 109-110

40. Tanaka F, Takahashi T, Matsuzoe S, et al (2013) Child-operated telepresence robot: a field trial connecting classrooms between Australia and Japan. In: 2013 IEEE/RSJ international conference on intelligent robots and systems. IEEE, Tokyo, pp 5896-5901

41. Tanaka F, Takahashi T, Matsuzoe S, et al (2014) Telepresence robot helps children in communicating with teachers who speak a different language. In: Proceedings of the 2014 ACM/IEEE international conference on human-robot interaction - HRI '14. ACM Press, Bielefeld, Germany, pp 399-406

42. Edwards A, Edwards C, Spence PR et al (2016) Robots in the classroom: Differences in students' perceptions of credibility and learning between "teacher as robot" and "robot as teacher." Com- 
put Hum Behav 65:627-634. https://doi.org/10.1016/j.chb.2016. 06.005

43. Hartsell-Gundy J, Johnson EO, Kromer J (2015) Testing telepresence: remote reference service via robotics. RUSQ 55:118-122. https://doi.org/10.5860/rusq.55n2.118

44. Sampsel D, Bharwani G, Mehling D, Smith S (2011) Robots as faculty: Student and faculty perceptions. Clin Simul Nurs 7:e209-e218. https://doi.org/10.1016/j.ecns.2010.02.009

45. Shaw RJ, Molloy M, Vaughn J et al (2018) Telepresence robots for pediatric clinical simulations: feasibility and acceptability. Pediatr Nurs 44:39-43

46. Zhang M, Duan P, Zhang Z, Esche S (2018) Development of telepresence teaching robots with social capabilities. In: Proceedings of the ASME 2018. American Society of Mechanical Engineers, Pittsburgh, Pennsylvania, USA, pp 1-11

47. United Nations Educational, Scientific and Cultural Organization (2021) Education: From disruption to recovery. In: UNESCO. https://en.unesco.org/covid19/educationresponse

48. World Health Organization (2021) WHO Coronavirus (COVID19) dashboard. https://covid19.who.int/

49. Holder J (2021) Tracking Coronavirus vaccinations around the world. The New York Times 9

50. Anderson J, Rainie L, Vogels EA (2021) A plurality of experts think sweeping societal change will make life worse for most people as greater inequality, rising authoritarianism and rampant misinformation take hold in the wake of the COVID-19 outbreak. Still, a portion believe life will be better in a 'tele-everything' world where workplaces, health care and social activity improve. In: Pew Research Center: Internet \& Technology. https:// www.pewresearch.org/internet/2021/02/18/experts-say-the-newnormal-in-2025-will-be-far-more-tech-driven-presenting-morebig-challenges/

51. Mavridis N, Quack E, Kai W (2021) Leveraging artificial intelligence and digital tech to help citizens, societies, and economies survive and strive during pandemics. In: Gruenwald L, Jain S, Groppe $S$ (eds) Leveraging artificial intelligence in global epidemics. Academic Press, pp 29-69

52. Orlikowski WJ, Gash DC (1994) Technological frames: making sense of information technology in organizations. ACM Trans Inf Syst 12:174-207. https://doi.org/10.1145/196734.196745

53. Vallor S (2011) Carebots and caregivers: sustaining the ethical ideal of care in the twenty-first century. Philos Technol 24:251-268. https://doi.org/10.1007/s13347-011-0015-x

54. Frennert S, Aminoff H, Östlund B (2021) Technological frames and care robots in eldercare. Int J Soc Robotics 13:311-325. https://doi.org/10.1007/s12369-020-00641-0

55. Nielsen JA, Andersen KN, Sigh A (2016) Robots conquering local government services: a case study of eldercare in Denmark. IP 21:139-151. doi:https://doi.org/10.3233/IP-160381

56. Fathema N, Shannon D, Ross M (2015) Expanding the Technology Acceptance Model (TAM) to examine faculty use of learning management systems (LMSs) in higher education institutions. J Online Learn Teach 11:210-232

57. Gibson SG, Harris ML, Colaric SM (2008) Technology acceptance in an academic context: faculty acceptance of online education. J Educ Bus 83:355-359. https://doi.org/10.3200/JOEB.83. 6.355-359

58. Teo T, Lee CB, Chai CS (2007) Understanding pre-service teachers' computer attitudes: applying and extending the technology acceptance model: Understanding pre-service teachers' computer attitudes. J Comput Assist Learn 24:128-143. https://doi.org/10. 1111/j.1365-2729.2007.00247.x

59. Chow M, Herold DK, Choo T-M, Chan K (2012) Extending the Technology Acceptance Model to explore the intention to use Second Life for enhancing healthcare education. Comput Educ 59:1136-1144. https://doi.org/10.1016/j.compedu.2012.05.011
60. Venkatesh V, Davis FD (2000) A theoretical extension of the technology acceptance model: four longitudinal field studies. Manage Sci 46:186-204. https://doi.org/10.1287/mnsc.46.2.186.11926

61. Venkatesh V, Bala H (2008) Technology Acceptance Model 3 and a research agenda on interventions. Decis Sci 39:273-315. https:// doi.org/10.1111/j.1540-5915.2008.00192.x

62. Bloss R (2011) High school student goes to class robotically. Ind Robot Int J 38:465-468. https://doi.org/10.1108/ 01439911111154027

63. Fels DI, Waalen JK, Zhai S, Weiss P (Tamar) (2001) Telepresence under exceptional circumstances: enriching the connection to school for sick children. In: INTERACT. pp 617-524

64. Abe K, Shiomi M, Pei Y et al (2018) ChiCaRo: Tele-presence robot for interacting with babies and toddlers. Adv Robot 32:176-190. https://doi.org/10.1080/01691864.2018.1434014

65. Wu X, Thomas R, Drobina E, et al (2017) An evaluation of a telepresence robot: User testing among older adults with mobility impairment. In: Proceedings of the companion of the 2017 ACM/IEEE international conference on human-robot interaction. ACM, Vienna Austria, pp 325-326

66. Park E (2013) The adoption of tele-presence systems: Factors affecting intention to use tele-presence systems. Kybernetes 42:869-887. https://doi.org/10.1108/K-01-2013-0013

67. Mou J, Shin D-H, Cohen J (2017) Understanding trust and perceived usefulness in the consumer acceptance of an e-service: a longitudinal investigation. Behav Inf Technol 36:125-139. https:// doi.org/10.1080/0144929X.2016.1203024

68. Raes A, Depaepe F (2020) A longitudinal study to understand students' acceptance of technological reform. When experiences exceed expectations. Educ Inf Technol 25:533-552. https://doi. org/10.1007/s10639-019-09975-3

69. Berisha A, Kölle R, Griesbaum J (2015) Acceptance of telepresence robots during group work. In: Pehar F, Schlögl C, Wolff C (eds) Re: inventing information science in the networked society. Proceedings of the 14th international symposium on information science (ISI 2015). Zadar, Croatia, pp 350-356

70. Carranza KAR, Day NJB, Lin LMS, et al (2018) Akibot: a telepresence robot for medical teleconsultation. In: 2018 IEEE 10th international conference on humanoid, nanotechnology, information technology, communication and control, environment and management (HNICEM). IEEE, Baguio City, Philippines, pp 1-4

71. Yun S-S, Kim M, Choi M-T (2013) Easy interface and control of tele-education robots. Int J Soc Robotics 5:335-343. https://doi. org/10.1007/s12369-013-0192-0

72. Fishbein M, Ajzen I (1975) Belief, attitude, intention, and behavior: an introduction to theory and research. Addison-Wesley, Reading

73. Bae I (2018) Public acceptance of fundamental rights via a telepresence robot and a video call stand in South Korea. Int J Soc Robotics 10:503-517. https://doi.org/10.1007/s12369-017-04534

74. Kuzuoka H, Furusawa Y, Kobayashi N, Yamazaki K (2007) Effect of displaying a remote operator's face on a media robot. In: 2007 international conference on control, automation and systems. IEEE, Seoul, South Korea, pp 758-761

75. Schepers J, Wetzels M (2007) A meta-analysis of the technology acceptance model: investigating subjective norm and moderation effects. Inf Manage 44:90-103. https://doi.org/10.1016/j.im. 2006.10.007

76. Choi G, Chung H (2013) Applying the technology acceptance model to social networking sites (SNS): impact of subjective norm and social capital on the acceptance of SNS. Int J HumanComput Interact 29:619-628. https://doi.org/10.1080/10447318. 2012.756333 
77. Im I, Kim Y, Han H-J (2008) The effects of perceived risk and technology type on users' acceptance of technologies. Inf Manage 45:1-9. https://doi.org/10.1016/j.im.2007.03.005

78. Lutz RJ, Reilly PJ (1974) An exploration of the effects of perceived social and performance risk on consumer information acquisition. In: Ward S, Wright P (eds) NA: Advances in Consumer Research, vol 01. Association for Consumer Research. Ann Arbor, MI, pp 393-405

79. Huang W, Schrank H, Dubinsky AJ (2004) Effect of brand name on consumers' risk perceptions of online shopping. J Consum Behav 4:40-50. https://doi.org/10.1002/cb.156

80. Newhart VA (2014) Virtual inclusion via telepresence robots in the classroom. In: Proceedings of the extended abstracts of the 32nd annual ACM conference on Human factors in computing systems - CHI EA '14. ACM Press, Toronto, Ontario, Canada, pp 951-956

81. Bell J, Cain W, Peterson A, Cheng C (2016) From 2D to Kubi to doubles: designs for student telepresence in synchronous hybrid classrooms. IJDL 7:19-33. https://doi.org/10.14434/ijdl. v7i3.19520

82. Cain W, Bell J, Cheng C (2016) Implementing robotic telepresence in a synchronous hybrid course. In: 2016 IEEE 16th international conference on advanced learning technologies (ICALT). IEEE, Austin, TX, USA, pp 171-175

83. Gleason BW, Greenhow C (2017) Hybrid education: The potential of teaching and learning with robot-mediated communication. OLJ 21:159-176. Doi:https://doi.org/10.24059/olj.v21i4.1276

84. Tsui KM, Desai M, Yanco HA, Uhlik C (2011) Exploring use cases for telepresence robots. In: Proceedings of the 6th international conference on Human-robot interaction. ACM, pp 11-18

85. Savela N, Turja T, Oksanen A (2018) Social acceptance of robots in different occupational fields: a systematic literature review. Int J of Soc Robotics 10:493-502. https://doi.org/10.1007/s12369017-0452-5

86. Lee MK, Takayama L (2011) "Now, I have a body": Uses and social norms for mobile remote presence in the workplace. In: Proceedings of the SIGCHI conference on human factors in computing systems. ACM Press, Vancouver, BC, Canada, pp 33-42

87. Takayama L, Go J (2012) Mixing metaphors in mobile remote presence. In: Proceedings of the ACM 2012 conference on computer supported cooperative work-CSCW '12. ACM Press, Seattle, Washington, USA, p 495

88. Sampsel D, Vermeersch P, Doarn CR (2014) Utility and effectiveness of a remote telepresence robotic system in nursing education in a simulated care environment. Telemed e-Health 20:1015-1020. https://doi.org/10.1089/tmj.2014.0038

89. Reese Q (2020) Texas A\&M student brings Penn State senior with cancer to classroom virtually. The Daily Collegian

90. Schleifer S (2018) Kubi, a Helpful Robot, Lets Students Take Classes Remotely. Colorado Arts and Sciences Magazine

91. Rose J, Fogarty G (2006) Determinants of perceived usefulness and perceived ease of use in the technology acceptance model: Senior consumers' adoption of self-service banking technologies. In: Proceedings of the 2nd Biennial conference of the academy of world business, marketing and management development: business across borders in the 21 st century. Academy of World Business, Marketing and Management Development. pp 122-129

92. Hansen JM, Saridakis G, Benson V (2018) Risk, trust, and the interaction of perceived ease of use and behavioral control in predicting consumers' use of social media for transactions. Comput Hum Behav 80:197-206. https://doi.org/10.1016/j.chb.2017.11. 010

93. Teo T (2011) Factors influencing teachers' intention to use technology: Model development and test. Comput Educ 57:2432-2440. https://doi.org/10.1016/j.compedu.2011.06.008
94. Dowling GR (1986) Perceived risk: the concept and its measurement. Psychol Mark 3:193-210. https://doi.org/10.1002/mar. 4220030307

95. Comrey AL, Lee HB (1992) A first course in factor analysis, 2nd edn. Lawrence Erlbaum Associates Inc, New Jersey

96. Peterson RA (1994) A meta-analysis of Cronbach's coefficient alpha. J Consum Res 21:381-391. https://doi.org/10.1086/209405

97. Shelby LB (2011) Beyond Cronbach's alpha: considering confirmatory factor analysis and segmentation. Hum Dimens Wildl 16:142-148. https://doi.org/10.1080/10871209.2011.537302

98. Taber KS (2018) The use of Cronbach's alpha when developing and reporting research instruments in science education. Res Sci Educ 48:1273-1296. https://doi.org/10.1007/s11165-016-9602-2

99. Tavakol M, Dennick R (2011) Making sense of Cronbach's alpha. Int J Med Educ 2:53-55. https://doi.org/10.5116/ijme.4dfb.8dfd

100. van Griethuijsen RALF, van Eijck MW, Haste H et al (2015) Global patterns in students' views of science and interest in science. Res Sci Educ 45:581-603. https://doi.org/10.1007/s11165014-9438-6

101. Raaijmakers QAW (1999) Effectiveness of different missing data treatments in surveys with Likert-type data: introducing the relative mean substitution approach. Educ Psychol Measur 59:24. https://doi.org/10.1177/0013164499595001

102. Bentler PM, Chou C-P (1987) Practical issues in structural equation modeling. Sociol Methods Res 16:78-117. https://doi.org/10. 1177/0049124187016001004

103. Petraitis PS, Dunham AE, Niewiarowski PH (1996) Inferring multiple causality: the limitations of path analysis. Funct Ecol 10:421. https://doi.org/10.2307/2389934

104. Thompson RL, Higgins CA, Howell JM (1994) Influence of experience on personal computer utilization: testing a conceptual model. J Manag Inf Syst 11:167-187. https://doi.org/10.1080/ 07421222.1994 .11518035

105. Lau S-H, Woods PC (2009) Understanding the behavior changes in belief and attitude among experienced and inexperienced learning object users. Comput Educ 52:333-342. https://doi.org/10. 1016/j.compedu.2008.09.002

106. Scherbaum CA (2006) A basic guide to statistical research and discovery: Planning and selecting statistical analyses. In: Leong FTL, Austin JT (eds) The psychology research handbook: a guide for graduate students and research assistants, 2nd edn. SAGE Publications Inc, Thousand Oaks, CA, pp 275-292

107. Schumacker RE, Lomax RG (2004) A beginner's guide to structural equation modeling, 2nd edn. Lawrence Erlbaum Associates Inc, Mahwah, NJ

108. Box GEP, Cox DR (1964) An analysis of transformations. J Roy Stat Soc: Ser B (Methodol) 26:211-252

109. Tabachnick BG, Fidell LS (2019) Using multivariate statistics, 7th ed. Pearson, NY, NY

110. Osborne JW, Waters E (2002) Four assumptions of multiple regression that researchers should always test. Pract Assess Res Eval 8:1-5. https://doi.org/10.7275/r222-hv23

111. Dunlap JC, Lowenthal PR (2009) Tweeting the night away: using Twitter to enhance social presence. J Inf Syst Educ 20:129-135

112. Rasmussen JL, Dunlap WP (1991) Dealing with nonnormal data: parametric analysis of transformed data vs nonparametric analysis. Educ Psychol Measur 51:809-820

113. Lee DK (2020) Data transformation: a focus on the interpretation. Korean J Anesthesiol 73:503-508. https://doi.org/10.4097/ kja.20137

114. West SG, Taylor AB, Wu W (2012) Model fit and model selection in structural equation modeling. In: Hoyle RH (ed) Handbook of structural equation modeling. Guilford Press, pp 209-231

115. MacKinnon DP, Lockwood CM, Williams J (2004) Confidence limits for the indirect effect: distribution of the product and resam- 
pling methods. Multivar Behav Res 39:99-128. https://doi.org/10. 1207/s15327906mbr3901_4

116. Nuttall AK, Froyen LC, Skibbe LE, Bowles RP (2019) Maternal and paternal depressive symptoms, home learning environment, and children's early literacy. Child Psychiatry Hum Dev 50:681-691. https://doi.org/10.1007/s10578-019-00872-x

117. Feng C, Wang H, Lu N et al (2014) Log-transformation and its implications for data analysis. Shanghai Arch Psychiatry 26:5. https://doi.org/10.3969/j.issn.1002-0829.2014.02.009

118. Benson J, Fleishman JA (1994) The robustness of maximum likelihood and distribution-free estimators to non-normality in confirmatory factor analysis. Qual Quant 28:117-136. https://doi. org/10.1007/BF01102757

119. Kaplan D (2009) Structural equation modeling: foundations and extensions, 2nd ed. SAGE Publications, Inc

120. Hu L, Bentler PM (1998) Fit indices in covariance structure modeling: Sensitivity to underparameterized model misspecification. Psychol Methods 3:424-253. https://doi.org/10.1037/1082989X.3.4.424

121. Bentler PM, Bonett DG (1980) Significance tests and goodness of fit in the analysis of covariance structures. Psychol Bull 88:588-606. https://doi.org/10.1037/0033-2909.88.3.588

122. Byrne BM (1998) Structural equation modeling with LISREL, PRELIS, and SIMPLIS: basic concepts, applications, and programming. Lawrence Erlbaum Associates Inc, Mahwah, NJ

123. MacCallum RC, Browne MW, Sugawara HM (1996) Power analysis and determination of sample size for covariance structure modeling. Psychol Methods 1:130-149. https://doi.org/10.1037/ 1082-989X.1.2.130

124. MacKinnon DP, Lockwood CM, Hoffman JM et al (2002) A comparison of methods to test mediation and other intervening variable effects. Psychol Methods 7:83-104. https://doi.org/10. 1037/1082-989X.7.1.83

125. Henderson R, Divett MJ (2003) Perceived usefulness, ease of use and electronic supermarket use. Int J Hum Comput Stud 59:383-395. https://doi.org/10.1016/S1071-5819(03)00079-X

126. Senko C, Hulleman CS, Harackiewicz JM (2011) Achievement Goal Theory at the crossroads: old controversies, current challenges, and new directions. Educ Psychol 46:26-47. https://doi. org/10.1080/00461520.2011.538646

127. Pintrich PR (2000) An achievement goal theory perspective on issues in motivation terminology, theory, and research. Contemp Educ Psychol 25:92-104. https://doi.org/10.1006/ceps. 1999.1017

128. Manson SM (2001) Simplifying complexity: a review of complexity theory. 10

129. Schunk DH (2012) Learning theories: an educational perspective, 6th edn. Pearson, Boston

130. Rantanen T, Lehto P, Vuorinen P, Coco K (2018) The adoption of care robots in home care: a survey on the attitudes of Finnish home care personnel. J Clin Nurs 27:1846-1859. https://doi.org/ 10.1111/jocn. 14355

131. Piçarra N, Giger J-C (2018) Predicting intention to work with social robots at anticipation stage: assessing the role of behavioral desire and anticipated emotions. Comput Hum Behav 86:129-146. https://doi.org/10.1016/j.chb.2018.04.026

132. Abdullah F, Ward R, Ahmed E (2016) Investigating the influence of the most commonly used external variables of TAM on students' perceived ease of use (PEOU) and perceived usefulness (PU) of e-portfolios. Comput Hum Behav 63:75-90. https://doi. org/10.1016/j.chb.2016.05.014

133. Lu H, Hsu C, Hsu H (2005) An empirical study of the effect of perceived risk upon intention to use online applications. Info Mngmnt Comp Security 13:106-120. https://doi.org/10.1108/ 09685220510589299
134. Belanche D, Casaló LV, Guinalíu M (2012) Website usability, consumer satisfaction and the intention to use a website: the moderating effect of perceived risk. J Retail Consum Serv 19:124-132. https://doi.org/10.1016/j.jretconser.2011.11.001

135. Gay G (2002) Preparing for culturally responsive teaching. J Teach Educ 53:106-116

136. Lee CD (2003) Toward a framework for culturally responsive design in multimedia computer environments: cultural modeling as a case. Mind Cult Act 10:42-61. https://doi.org/10.1207/ S15327884MCA1001_05

137. Kaplan F (2004) Who is afraid of the humanoid? Investigating cultural differences in the acceptance of robots. Int J Human Robot 01:465-480. https://doi.org/10.1142/S0219843604000289

138. Riek LD, Mavridis N, Antali S, et al (2010) Ibn Sina steps out: Exploring Arabic attitudes toward humanoid robots. In: Dautenhahn K, Saunders J (eds) Proceedings of the second international symposium on new frontiers in human-robot interaction. Leicester, UK, pp 88-94

139. Fitter NT, Strait M, Bisbee E, et al (2021) You're wigging me out!: Is personalization of telepresence robots strictly positive? In: Proceedings of the 2021 ACM/IEEE international conference on human-robot interaction. ACM, Boulder CO USA, pp 168-176

140. Strait M, Ramos AS, Contreras V, Garcia N (2018) Robots racialized in the likeness of marginalized social identities are subject to greater dehumanization than those racialized as white. In: 2018 27 th IEEE international symposium on robot and human interactive communication (RO-MAN). IEEE, Nanjing, pp 452-457

141. Eyssel F, Hegel F (2012) (S)he's got the look: gender stereotyping of robots. J Appl Soc Psychol 49:2213-2230. https://doi.org/10. 1111/j.1559-1816.2012.00937.x

142. Ratan R, Rikard R, Wanek C, et al (2016) Introducing avatarification: An experimental examination of how avatars influence student motivation. In: 2016 49th Hawaii international conference on system sciences (HICSS). IEEE, Koloa, HI, USA, pp 51-59

143. Teng C-I (2017) Impact of avatar identification on online gamer loyalty: Perspectives of social identity and social capital theories. Int J Inf Manage 37:601-610. https://doi.org/10.1016/j.ijinfomgt. 2017.06.006

144. Pasfield-Neofitou S, Huang H, Grant S (2015) Lost in second life: virtual embodiment and language learning via multimodal communication. Educ Tech Res Dev 63:709-726. https://doi.org/ 10.1007/s11423-015-9384-7

145. Blizzard Entertainment (2004) World of Warcraft. Blizzard Entertainment, Irvine, CA

146. Infinity Ward, Treyarch, Sledgehammer Games, Raven Software (2021) Call of Duty. Activision

147. Ballard ME, Welch KM (2017) Virtual warfare: cyberbullying and cyber-victimization in MMOG play. Games Culture 12:466-491. https://doi.org/10.1177/1555412015592473

148. Mavridis N, Petychakis M, Tsamakos A et al (2010) FaceBots: Steps towards enhanced long-term human-robot interaction by utilizing and publishing online social information. Paladyn $\mathbf{J}$ Behav Robotics 1:169-178. https://doi.org/10.2478/s13230-0110003-y

149. Fleckenstein KS (2005) Faceless students, virtual places: emergence and communal accountability in online classrooms. Comput Compos 22:149-176. https://doi.org/10.1016/j.compcom. 2005.02.003

150. Ames MG (2013) Managing mobile multitasking: the culture of iPhones on Stanford campus. In: Proceedings of the 2013 conference on computer supported cooperative work-CSCW '13. ACM Press, San Antonio, Texas, p 1487

151. Roselius T (1971) Consumer rankings of risk reduction methods. J Mark 35:55-61. https://doi.org/10.2307/1250565

152. Pavlou PA (2003) Consumer acceptance of electronic commerce: Integrating trust and risk with the technology acceptance 
model. Int J Electron Commer 7:101-134. https://doi.org/10. 1080/10864415.2003.11044275

153. Li Y-H, Huang J-W (2009) Applying theory of perceived risk and technology acceptance model in the online shopping channel. Int J Econ Manage Eng 3:505-511. https://doi.org/10.5281/zenodo. 1085603

154. Faqih KMS (2013) Exploring the influence of perceived risk and internet self-efficacy on consumer online shopping intentions: perspective of technology acceptance model. Int Manage Rev 9(67-77):88

Publisher's Note Springer Nature remains neutral with regard to jurisdictional claims in published maps and institutional affiliations.

Ming Lei is a Ph.D. candidate in Educational Psychology and Educational Technology at Michigan State University. Ming's research focuses on creating inclusive learning environments. His service work involves regional and international collaborations with higher education programs in instructional technology, leadership, and design.

Ian Clemente is a Ph.D. candidate in Educational Psychology and Educational Technology at Michigan State University. His research interests are centered on cognitive flexibility, use of digital technologies and Web search strategies for online teaching and learning, and development of learning environments aimed at institutional adaptiveness and cultural responsiveness to the evolving needs of students, teachers and communities.
Haixia Liu is a Ph. D. in Education Psychology and Education Technology from Michigan State University and she is currently serving as a faculty of instruction in Brooks College in Grand Valley State University. Her research interests sits at the intersection of language and culture education, behavioral psychology, technology adoption and communication studies.

John Bell is Professor Emeritus (fixed term) of the College of Education at Michigan State University. He previously served as creator and director of the CEPSE/COE Design Studio in the and co-coordinator of the Hybrid Educational Psychology and Educational Technology $\mathrm{Ph} . \mathrm{D}$. program. His research interests focused on hybrid and online teaching and learning, including augmented reality and robotic telepresence, and idea-based teaching and learning using technology. 